\title{
"EL JOVEN RESPONSABLE DE SU CASTIGO. SU TRÁNSITO EN EL ESTADO PENAL". ANALISIS DEL DISCURSO PROFESIONAL COMO PARTE DEL DISPOSITIVO PENAL JUVENIL
}

\section{'THE YOUNG MAN RESPONSIBLE FOR HIS PUNISHMENT. HIS TRANSIT THROUGH THE PENAL STATE'. EXPERT DISCOURSE ANALYSIS AS PART OF YOUTH CRIMINAL DISPOSITIVE}

\section{Paulo Damián Aniceto}

\section{RESUMEN}

En este trabajo, analizamos los enunciados de profesionales que intervienen en la administración del castigo penal juvenil en la provincia de Córdoba, Argentina, desde 2011. Desde presupuestos de la sociolingüística y la semiótica jurídica landowskiana, reconocemos los informes psicológicos producidos en el contexto de una prisión juvenil como expresiones del discurso experto que interpelan un joven responsable de su castigo. La conclusión que desprendemos establece un posicionamiento reflexivo en relación con las propiedades comunes a los discursos de la responsabilización. Su aparición regular en el campo judicial instituye y repone, recursivamente, una norma sobre el joven reprochable y reasegura para el yo-enunciador experto un doble estatus: pericial y jurídico.

Palabras claves: responsabilidad penal juvenil; complejo esperanza; discurso experto.

\section{ABSTRACT}

In this paper, we analyze the utterances of professionals who act in the administration of youth criminal punishment in Córdoba, Argentina, since 2011. From premises of sociolinguistics and landowskianan legal semiotics, we recognize the psychological reports produced in a youth prison as expressions of the expert discourse that interpellate a young responsive for his punishment. The conclusion we draw set up a reflexive position about the properties shared by utterances of responsibilization. Its regular emergency on judicial field recursively institutes and replaces a norm referring to blamewortby young and guarantees a double status for the expert I-utterer: expert and legal.

Keywords: youth criminal responsibility; complejo esperanza; expert discourse.

(...) En imputables se dice declaración del imputado y en menores de 15 años se les toman exposiciones informativas, que en la práctica leés el becho que se le atribuye y él declara o no declara (...). Son juegos de lenguaje, sigue siendo

\footnotetext{
* Universidad Nacional de Córdoba, Córdoba, Argentina. paulodamiananiceto@gmail.com Orcid: https://orcid.org/0000-0001-8912-0444
} 
una indagatoria, no sé si esto te sirve, en la práctica el cbico está preso, sigue poniendo el cuerpo en el Complejo Esperanza (Asesora de Niñez y Juventud del Fuero Penal Juvenil de la Provincia de Córdoba)

La cuestión del castigo debe inscribirse en una teoría realista de la igualdad que baga a la sociedad responsable tanto de su pasado como de su presente (FASSIN, 2018 [2017], p. 194)

\section{INTRODUCCIÓN}

En este estudio, informamos los resultados de un análisis semiótico de un conjunto de textos expertos, que emerge en el contexto de una prisión de jóvenes supuestos autores de delitos en Córdoba, Argentina. Una parte del material que conforma nuestro corpus se compone de los informes psicológicos y sociales realizados por profesionales de los equipos técnicos en una de las prisiones para jóvenes de esta ciudad.

Los informes elevados al juez en cada procedimiento, incluidos los elaborados en el contexto de encierro que abordamos aquí, conforman un discurso jurídicamente lego pero tributan a un dispositivo de enunciación, a una episteme identificada con una competencia jurídica profesional.

Los textos de estos informes en los que emerge esta competencia prevalecientemente profesional-administrativa, codifican el sentido que el tránsito penal de los jóvenes en la prisión de Córdoba tiene a los ojos de los profesionales. En definitiva, estos textos son los operadores de un vínculo: el que une la competencia profesional-jurídica (que no es la del psicólogo, pero sí la que emerge en sus informes, que el juez subsumirá a una racionalidad de la práctica procesal), a una competencia profesional-administrativa (que no es la del juez pero sí la de la sentencia que retoma los informes). El sentido codificado del tránsito penal de los jóvenes en los informes y las sentencias está entonces determinado por el registro profesional y el tecnolecto específico del campo jurídico.

El principio organizador de este fenómeno multiforme de semiotización de la penalidad juvenil, de sus procedimientos de circulación, lo que puede decirse y quién puede decirlo, es el Estado. Las competencias administrativa y jurídica unidas en la codificación de los informes sobre los jóvenes presos son desplegadas por profesionales que se desempeñan en el campo burocrático estatal. La lógica que domina la producción, la circulación y los efectos de los informes que semiotizan el tránsito de los jóvenes presos en Córdoba es la de los dispositivos tecnológicos y la capacidad burocrática del Estado penal.

El contexto de producción de estos informes técnicos sobre los jóvenes presos es el que Wacquant (2013 [2009]) caracteriza al reconocer una triple 
transformación del Estado: "la amputación de su brazo económico, la retracción de su seno social y la ampliación generalizada de su mano penal" (WACQUANT, 2013 [2009], p. 33). Pero los fenómenos simultáneos del recorte del Estado caritativo y el despliegue del Estado penal no son sólo contiguos temporalmente. Son el resultado de la focalización del discurso y de la práctica estatales sobre el tema de la seguridad.

En el caso que nos ocupa aquí, el de la prisionización de jóvenes en Córdoba, vale preguntarnos por el contexto del empleo de las estrategias que los profesionales del Estado penal codifican la reclusión de los niños y adolescentes que selecciona. Fassin (2018 [2017]) lo hace en Punir. Une passion contemporaine: "chasta qué punto las cuestiones de calificación en materia de castigo son siempre apuestas morales y políticas?" (FASSIN, 2018 [2017], p. 68). En definitiva, el paso del Estado social al penal al que remite la triple transformación wacquantiana no se erige sobre el abandono de la gestión de la cuestión social. A esto se refiere Fassin (2018 [2017]), en otro tramo de su texto, al contestar a su pregunta en estos términos: "el tribunal puede a este respecto ser visto como el lugar por excelencia de la difracción de lo social a través del prisma de lo penal" (FASSIN, 2018 [2017], p. 169-170).

Las prácticas discursivas de los profesionales de la prisión juvenil de Córdoba que producen los informes que luego retomará el juez se relacionan por múltiples vías con el castigo que el Estado penal inflige a los jóvenes. Esta vinculación se explica en parte porque las condiciones de producción tanto del discurso que construye un joven responsable de su castigo como de la historia penal del joven son sociales y políticas.

En cuanto a las condiciones del discurso, ese doble carácter se manifiesta en que, por un lado, las actividades rituales que preceden a estos informes (las entrevistas que los profesionales realizan con los jóvenes) están sujetas a gramáticas discursivas análogas a las que rigen las comparecencias ante un tribunal. Por otro lado, la periodicidad de estos ritos y de la escritura, y su categorización en tanto que prueba informativa operan reforzando un estatus especial del enunciador inscripto en estos textos.

Asumimos una perspectiva teórica que toma presupuestos de la teoría de la enunciación, de la sociosemiótica landowskiana (LANDOWSKI, 1993; LANDOWSKI et al en GREIMAS, 1980 [1976]) y, sobre todo, de la tradición francesa que enfatiza en la interacción de las formaciones discursivas al interior de distintos campos discursivos (MAINGUENEAU, 1984). Analizamos las estrategias argumentativas mediante las cuales los discursos de profesionales aparecen en el campo judicial configurado en las causas que implican medidas 
de prisión ${ }^{1}$ de niños y adolescentes ${ }^{2}$. El abordaje de las estrategias del discurso experto desde esta perspectiva integrada supone reconocer que los profesionales de los equipos técnicos que producen la prueba informativa se identifican con sujetos de enunciación con pretensión de corrección jurídica. En sus performances enunciativas, presentan los modelos de juventud irreprochable que construyen como si fueran la norma de referencia que no hacen más que citar.

Elyo-enunciador inscripto en los enunciados informativos, ocupa un posicionamiento argumentativo (PLANTÍN, 2012 [2005]). Esta es la superficie de emergencia de un sujeto sintáctico, un proponente, que, en términos de Christian Plantín (2012 [2005]), "soporta la carga de la prueba entre los interlocutores" y, al mismo tiempo, normaliza los esquemas culturales de percepción, o la doxa: creencias sobre los jóvenes para las cuales "no pesa la carga de la prueba y entonces son consideradas normales" (68).

Las prácticas discursivas que se adjudican esta carga de la argumentación, o carga lingüística (STYGALL, 1994), se ejercen con regularidad en el Fuero Penal Juvenil cordobés. Entre las condiciones de posibilidad de este campo discursivo, y de su matriz común de inteligibilidad, se encuentra nada menos que la conformación histórica de un dispositivo de judicialización y penalización de los jóvenes y la sedimentación de un plexo de normas que trabajan, entran en acción, justificando la persistencia y las readecuaciones del dispositivo. En octubre de 2005, se sancionó la Ley nacional de Promoción y Protección Integral de los Derechos de las Niñas, Niños y Adolescentes ${ }^{3}$ (en adelante, Ley de Protección Integral), y, en mayo de 2011, se produjo la la adecuación (parcial) de la legislación de la Provincia de Córdoba ${ }^{4}$ en esta materia. Estos dos eventos legislativos son pasos en el camino de amoldar el paradigma legal referido a la infancia y la juventud al modelo basado en

1. Los tres edificios que actualmente funcionan en el predio del Complejo reciben el rótulo formal de Centros Socioeducativos, donde los jóvenes varones supuestos autores y los declarados responsables de un delito, se encuentran privados de su libertad con un fin tuitivo (de protección). Sin embargo, a partir de sucesivas visitas al complejo, el tránsito por los sectores de los tres módulos, y las entrevistas al personal desempeñado allí, tomamos la opción de denominar este espacio, su mobiliario, sus rutinas, sus prácticas características y el régimen que regula tanto la circulación de los cuerpos, como las rutinas y las prácticas, prisión.

2. Como aclararemos a continuación, nuestro abordaje se limita a analizar los sentidos producidos y circulantes entre el Fuero Penal Juvenil cordobés y la prisión donde son confinados los niños y adolescentes varones, el Complejo Esperanza. Las niñas y adolescentes mujeres son encarceladas en el Centro Socioeducativo para Adolescentes Mujeres, ubicado en el centro de la ciudad de Córdoba Capital.

3. Ley de Protección Integral de los Derechos de las Niñas, Niños y Adolescentes. Publicada en el Boletín Oficial de la República Argentina el 18 de abril de 2006.

4. Ley de Promoción y Protección Integral de los Derechos de las Niñas, Niños y Adolescentes. Publicada en el Boletín Oficial de la Provincia de Córdoba, el 03 de junio de 2011. 
derechos que emergió de la mano de la Convención sobre los Derechos del Niño, en 1989.

Ambas leyes argentinas forman parte de un conglomerado de discursos que referencian la transformación de las concepciones sobre el reproche penal juvenil como una tarea que podrá consumarse si se aplican estrictamente los lineamientos de la norma (LUCERO, 2013). Ambas emergieron como las promesas formales de adecuación de las respectivas prácticas administrativas, judiciales y penales al paradigma legal en ciernes. En orden al modelo legal de protección integral de derechos, los jóvenes constituyen ciudadanos con capacidad de exigir el cumplimiento de sus derechos, y no un objeto de protección del Estado (LUCERO, 2013).

\section{LA TRANSICIÓN A UN NUEVO PARADIGMA LEGAL EN ARGENTINA}

En Argentina, la transición a este modelo tuvo sus propios matices. Durante el siglo XX, prevaleció un esquema que articulaba objetos como pobres, desviados, delincuentes y peligrosos. Una estrategia representacional asumida por las instituciones oficiales organizaba las tensiones entre "excedencia social, precariado, juventud, pobreza, peligrosidad y segregación" (DAROQUI y LÓPEZ, 2012a, p. 59). Ahora bien, este esquema y las prácticas discursivas que lo actualizan sobrevivieron al tiempo, reformulando el dispositivo histórico de enunciación característico de las políticas públicas de control juvenil, que tienen en el Complejo una de sus sedes paradigmáticas.

A finales de la década de los 70', confluyeron en el mundo occidental la apertura neoliberal, la inflación de los sistemas penales y la consolidación de los modelos de sociedades excluyentes de la modernidad tardía (DAROQUI, LÓPEZ y CIPRIANO GARCÍA, 2012; GUEMUREMAN, 2011). En materia penal juvenil, el último gobierno militar de facto argentino firmó, en 1980, el decreto ley 22.278, que estableció el Régimen Penal de Minoridad vigente hasta hoy en todo el país. La persistencia de esta normativa garantiza la del dominio de nociones (CULIOLI, 1995) característico del paradigma tutelar. En materia prevencional y de protección de derechos, la ley nacional sancionada en 2005 derogó la Ley de Patronato de Menores de 1919, que, seis décadas antes del decreto dictatorial, establecía a partir de su artículo 14 un procedimiento aplicable a menores delincuentes. La Ley nacional de 2005 derogó el régimen Patronato pero no desvaneció sino formalmente el tenor tutelar de las prácticas. La permanencia rectora del decreto 22.278 en el ámbito penal otorga márgenes amplios de discrecionalidad a los jueces juveniles que, en orden a una concepción patrimonialista, "disponen" de los jóvenes toda vez que consideren, según un criterio que no están obligados a explicitar, que están "en peligro moral o material". 
La ley nacional de 2005 derogó la de Patronato de Menores y ordenó una nueva arquitectura institucional, que otorgó nuevas funciones a los organismos administrativos provinciales. En la provincia de Córdoba, sin embargo, el proceso de adecuación al sistema de protección integral fue discontinuo y, hasta hoy, incompleto (LUCERO, 2013).

En 2007, la ley provincial de adhesión a la norma nacional no garantizaba el principio de la desjudicialización de las problemáticas de protección integral (LUGONES, 2008). Además, no respetaba los contenidos mínimos de la ley nacional, que era (y es) aplicable directamente en todo el territorio argentino (SABSAY, 2006). Paradójicamente, tenía como espíritu (tal como llaman los juristas a la voluntad de poder encubierta del texto legal) adherir a los presupuestos de una ley que la adhesión misma no hacía más que suspender.

Además, desde 1994 hasta 2016, la vigencia del Código de Faltas5, criminalizaba prácticas como la de caminar en la vía pública, que designada merodeo (art. 85), o a la que se refería con el sintagma nominal ruidos que causen escándalos (art. 52). Los 22 años de este código aportaron a consolidar un singular sistema de categorizaciones del eje semántico juventud/delito. Su eficacia simbólica y sus efectos prácticos son marcas de un imaginario social extendido en Córdoba acerca de la inseguridad urbana, la juventud delictiva y las políticas de seguridad ciudadana (ROLDÁN y DAHBAR, 2013; HATHAZY, 2014; LERCHUNDI y BONVILLANI, 2014).

Finalmente, a mediados de 2011, la sanción de la ley provincial de Protección Integral saldó la deuda de la desjudicilización. Los juzgados prevencionales y correccionales, que conformaban un mismo fuero, se convirtieron, respectivamente, en el Fuero de Niñez, Juventud y Violencia Familiar, y en el Fuero Penal Juvenil. Sin embargo, la modalidad de los procedimientos penales establecida desde el artículo 82 en adelante en la ley provincial de 2011 se encuentra, en lo fáctico, en clara concordancia con el Régimen Penal de Minoridad de $1980^{6}$.

\subsection{El texto de la ley e la textura de la práctica}

Una reseña crítica de los contextos en los que se ejercen las prácticas legislativas, judiciales y administrativas, nos enfrenta al interrogante sobre lo que Daroqui y

5. Ley Provincial 8.431, derogada y sustituida por el Código de Convivencia Ciudadana (Ley provincia al 10.326) en marzo de 2016.

6. El organismo de Naciones Unidas especializado para el seguimiento de la aplicación de la Convención de los Derechos del Niño (CDN), en sus observaciones a la Argentina, manifestó preocupación porque el sistema de justicia de menores sigue estando administrado por la Ley $\mathrm{N}^{\mathrm{O}}$ 22278, a pesar de su incompatibilidad con la Convención. 
López (2012a) llaman, desde un enfoque foucaultiano, "formas de gobernabilidad de la cuestión social en relación con los jóvenes y el sistema penal" (DAROQUI y LÓPEZ, 2012a, p. 58). En esta dirección, debemos reconstruir exhaustivamente el sistema de prácticas y representaciones producidas efectivamente en el campo discursivo judicial. Y, entonces, poner en suspenso un supuesto que esconde una falacia argumentativa pero que, desde un enfoque mecanicista y formal, funciona como premisa de partida: las prácticas institucionales son calificables de adecuadas al paradigma legal de protección integral sencillamente porque son posteriores a la ley que fundó este paradigma, y justificables mediante la inclusión de los enunciados del texto legal.

Determinar, desde un enfoque contrapuesto, la inadecuación de las prácticas a las normas en un momento dado implica un trabajo arduo que aquí no llevaremos hasta el final, pero también, uno en relación con el cual el nuestro es subsidiario. Este enfoque es el continente o la sede tópica del nuestro.

Nuestro objetivo no es determinar la rigurosidad con que las prácticas ejercidas en esta prisión juvenil de Córdoba aplican la lex scripta (tarea, por cierto, valiosa y necesaria), sino identificar y explicar las estrategias mediante las cuales se suman a un conjunto discursivo (del cual la norma forma parte) que significa y resignifica a los jóvenes prisionizados (CLEMMER, 1958). Sin embargo, al mismo tiempo, nuestro trabajo se asienta sobre las bases de este programa más amplio porque quiere comprender las estrategias de los discursos que devienen judiciales en el marco de normas procesales. Estos discursos circulan reforzando un efecto de verdad que cubre el ejercicio de toda práctica judicial: presentan el poder de las instituciones oficiales como subsumido al poder de la norma.

\subsection{Las prácticas penales juveniles en Córdoba y sus sentidos}

Partimos de un presupuesto que asume que sobre esos discursos se construyen una serie regular de dominios referenciales, sobre la que emerge un objeto de discurso que funciona como el prototipo de la serie: el joven irreprocbable. El material donde reconocemos la emergencia de ese discurso se organiza en unidades de análisis: los informes periódicos de los psicólogos y los trabajadores sociales que entrevistan a los jóvenes y a sus familias, cuando los primeros ingresan a la prisión.

El Complejo Esperanza se extiende en un predio ubicado en las afueras de la ciudad de Córdoba, donde la SENAF ${ }^{7}$, el organismo de gobierno encargado, por la ley de 2011, de administrar la reclusión de los jóvenes seleccionados por el sistema

7. Secretaría de Niñez, Adolescencia y Familia (SENAF) de la Provincia de Córdoba. 
penal de la provincia. El predio se encuentra ubicado en el extremo sur de Córdoba Capital, a más de 14 kilómetros del límite sur del ejido urbano. No tiene barrios colindantes, ni transporte público directo, ni visibilidad desde la ruta, ni cartel de más un metro por cincuenta centímetros que lo anuncie. Por la vía que conecta la zona urbana con la rural ${ }^{8}$, se abre un camino angosto que finaliza, al cabo de un kilómetro, en el alambrado que delimita el predio. Pero el Complejo no carece sólo de barrios colindantes, como se ha dicho, sino de un barrio en cuyo croquis figurar. Está alejado de los barrios conectados con la zona urbana por una vía, Coronel Olmedo y Quebracho, y cercano del límite de la ciudad?.

Desde sus arrestos policiales en la vía pública, denominados tradicionalmente preventivos, los jóvenes se incorporan a un derrotero que implica el tránsito por las agencias que enlazan la cadena punitiva (lo policial, lo judicial y lo custodial) (DAROQUI y LÓPEZ, 2012b, p. 101). Las primeras horas de su encierro transcurren en la unidad judicial de una comisaría, desde la que el ayudante fiscal informa al juez (casi siempre telefónicamente) e inaugura, con esto, el estado de disposición. En los casos de delitos contra la propiedad, que en este estudio abarcan la totalidad, las instrucciones son generalmente las mismas: "certificar la edad", "disponer órdenes de allanamiento", "imputar el delito de robo", "realizar pericia psiquiátrica obligatoria", "hacer comparecer en el juzgado", "alojar en el centro socioeducativo dependiente de la SENAF". Ya sean imputables o inimputables, los jóvenes son entrevistados por el juez o su secretario y por la Asesora o su auxiliar en tanto que defensora pública.

De allí, se abren dos caminos posibles: el sobreseimiento y la liberación o la continuidad de la disposición del joven o la joven a cargo del juez, quien puede decidir darlo ${ }^{10}$ en guarda judicial a sus familiares mientras la investigación tiene desarrollo o encargar su internación en dos prisiones: en el CeSAM (prisión para Adolescentes Mujeres) o en el Complejo Esperanza (prisión de adolescentes varones).

En el sistema relativamente autónomo de categorías que emergen en el discurso experto que emerge en el contexto de esta última prisión reconocemos la

8. El Complejo se ubica a la altura Km 14 1⁄2 de esta vía, denominada Camino 60 Cuadras. En el punto de este tramo, el predio carcelario está exactamente al extremo de la vía.

9. Según uno de los entrevistados, años atrás, algunos decían que quedaba en Bower (fuera de los límites de la ciudad de Córdoba).

10. La categoría de la disposición, que se inscribe en el texto del decreto ley 22.278 , se sustrae al contenido del texto mismo y se constituye en el principio de un dominio nocional o paradigma de designaciones dentro del cual la relación entre el joven y el Estado es signada por una concepción patrimonialista: 'darlos en guarda' o 'nos dividimos los chicos, como expresó en una entrevista una trabajadora social al comentar sus tareas de acompañamiento a los jóvenes presos. 
presencia de actos de enunciación se adjudican la expertise de caracterizar al joven prisionizado y la mejor manera de transitar su prisión.

(1) (...) En el San Jorge ${ }^{11}$, ahora, hay 30 chicos. Y si llegara a estar completo, serían 40, pero más de eso no. Entonces, es un instituto chico, y eso hace que puedan tener muchas actividades, y que se pueda cumplir con todas. Nosotras administramos esas rutinas y actividades. Antes que llegáramos, estaba todo desorganizado, y nosotras hemos logrado eso, que se haya organizado (...) (Fragmento de entrevista 1 a Socioeducadora del Módulo IV, ex San Jorge).

(2) (...) lo que hacemos es acompañarlos individualmente. Para eso nosotras elegimos una modalidad que es dividir en tutorías. Cada una es como la referente. Nos dividimos los chicos. por perfil nuestro que ya nos conocemos cómo trabajamos y más o menos conocemos a los chicos si es que son reingresos (...) (Fragmento de entrevista 2 a Socioeducadora del Módulo IV, ex San Jorge).

(3) (...) tiene que ver más con la adaptación a la vida institucional, están en una institución cerrada (...) pero además tiene que haber un plus de decir ćpor qué el joven está en el sistema penal juvenil? Eso necesariamente no lo vas a tener en la primera entrevista, a lo mejor en la segunda, la tercera. Nosotros, como psicólogos que estamos hace tanto tiempo, no es lo mismo la primera intervención en el complejo, la primera vez que está encerrado en una institución cerrada de rejas, a un chico que es la cuarta vez que está (...) (Fragmento de entrevista 3 a Psicóloga de equipos técnicos de la SENAF).

Los jóvenes presos en el Complejo purgan un castigo sin pena. Son trasladados con esposas a las citas en los juzgados, un grupo de guardiacárceles los observa y los reprende, y realiza requisas periódicas en sus celdas, que, a una hora determinada del día, se cierran bajo llave, no reciben la visita de su familia sino dos días a la semana, en salas especiales, durante dos horas. Un dispositivo que tiene en las prisiones del Complejo su centro operativo, prisioniza a los jóvenes seleccionados por el sistema penal, los incluye en lo que en (3) es denominado 'la vida institucional' a la cual los jóvenes deben 'adaptarse' (CLEMMER, 1958, p. 98; GARLAND, 1999 [1990], p. 17; MESSUTI, 2008, p. 137.).

Los jóvenes imputables transcurren, muchas veces sin sentencia, el tiempo de su castigo en dos módulos, el I y el II, hasta hace poco llamados Horizontes y Nuevo Sol respectivamente. Los inimputables, por su parte, son encerrados en el Módulo IV o ex San Jorge. Ahora bien, en este complejo de prisiones, funciona un

11. San Jorge es el antiguo nombre de la prisión destinada al encierro de jóvenes no punibles, que hoy se llama Módulo IV. 
cuarto módulo, reconocido por los agentes de la SENAF y los operadores jurídicos como un espacio intermedio entre los módulos y el afuera: el Centro de Admisión y Diagnóstico (CAD). Este es el primer espacio físico que transitan todos los jóvenes, imputables e inimputables hasta llegar a la prisión de destino. Es en el CAD donde se pone en marcha la serie interpelaciones que apuestan a instituir las subjetividades delictivas en un muy complejo contexto de producción: el carcelario.

Este trabajo marca el inicio de la construcción de esa serie. La razón de distinguir esta instancia del castigo penal juvenil de las demás, emerge de la formulación de nuestra hipótesis de trabajo: los módulos del Complejo, donde los jóvenes permanecen presos desde su egreso del CAD hasta su liberación, son los espacios donde transcurre y se escenifica un proceso de interpelaciones que tiene como horizonte la subjetivación delictual de los jóvenes, y como punto de partida, el CAD.

Las primeras entrevistas que los psicólogos de esta prisión realizan a los jóvenes que ingresan al Complejo conforman la superficie de emergencia de un relato y una norma. En estas escenas rituales, se verbalizan los distintos estados del proceso de adecuación al sujeto transgresor que se prescribe para él. Si los discursos que reconocemos en los informes reenvían a esas escenas y estas, a su vez, al requerimiento de un punto de vista profesional que oriente la decisión judicial, es dable asignar en estos discursos la superficie de emergencia de la apuesta de subjetivación del joven jurídicamente irreprochable (y de su opuesto, el joven encerrado).

Un régimen de interpelación, entonces, no es sino una apuesta a la adecuación forzosa. El joven preso será responsable toda vez que asuma la sucesión de dos circunstancias, su estancia en libertad y su estancia en prisión, como un fenómeno derivado de una opción personal. En resumidas cuentas, el objeto de nuestro análisis está conformado por las estrategias de indagación desplegadas por la práctica discursiva profesional y por sus efectos de responsabilización.

A continuación, establecemos los lineamientos metodológicos que guiarán el abordaje semiótico del material en el que se instancia este régimen de interpelación.

\section{METODOLOGÍA}

\subsection{Material lingüístico del corpus}

Construimos nuestro corpus a partir de diferentes técnicas de recolección de datos. Por un lado, al cabo de tres visitas al Complejo, contamos con 14 entrevistas en profundidad realizadas a agentes del órgano oficial a cargo de las prisiones de 
los módulos I (ex Horizontez), II (ex Nuevo Sol) y IV (ex San Jorge). En otro orden, luego de 26 sesiones de consulta, durante el año 2018, contamos con los fichajes de 140 informes psicológicos y sociales, 37 sentencias (de declaraciones de responsabilidad y de cierres de juicios), además de autos interlocutorios y otros documentos considerados útiles en función de nuestros objetivos.

A los fines específicos de este trabajo, nos proponemos reconocer los efectos de sentido producidos en algunos de los discursos recolectados en esta etapa y destacar datos de nuestros informantes que aporten a la comprensión de las modalidades enunciativas de la práctica discursiva en el CAD del Complejo.

Un análisis semiótico del discurso experto es crítico en la medida en que parte del supuesto de la autolegitimación o de la hipótesis de que su funcionamiento en el campo discursivo jurídico se homologa al funcionamiento del discurso judicial (ANICETO, 2017a, ANICETO, 2017b; KILEY, 1996). Esto quiere decir que el discurso experto inscribe un enunciador autolegitimado que referencia la ley y, a la vez, controla sus derivas interpretativas: procede de acuerdo a una gramática jurídica. En este sentido, reconoceremos los específicos paradigmas designacionales (MORTUREUX, 1993) que emergen sobre este conjunto enunciativo. Si, como sostienen Landowski, Chabrol, Bucher y Fabbri (en GREIMAS, 1980 [1976]), uno de los aspectos esenciales de la práctica jurídica es la tarea, que se toma a cargo discretamente, de "nombrar y definir los objetos" (LANDOWSKI et al en GREIMAS p. 98.), no cabe más que señalar, que reponer la evidencia de esos actos de nombramiento y de definición con fuerza de ley.

Del análisis del corpus lingüístico, compuesto de esas interpelaciones con efectos de derecho (LANDOWSKI, 1993), concluimos acerca de un dominio de referentes que en los actos de enunciación de los informes es asociado con el objeto de discurso joven transgresor. El discurso experto emerge en el contexto de las medidas de prisión presentándose como el medio de refuerzo de un paradigma designacional y presentando ese refuerzo como una el signo de su inscripción en el paradigma legal protección integral de derechos.

\section{ANÁLISIS DEL CORPUS}

\subsection{El primer escenario de indagación}

El CAD funciona en dos edificios, uno administrativo, ubicado en la sede de la SENAF, ubicada en el centro de la ciudad de Córdoba, y otro carcelario, en el Complejo. La estadía de los jóvenes en esta primera prisión cumple el papel 
de establecer una primera descripción de los recursos con los que dispone el joven, en palabras de una de las psicólogas del centro, y de ofrecer al juez un panorama del funcionamiento de la dinámica familiar, en lo relacionado con diversos objetos, nombrados la mayoría de las veces en estas fórmulas: situación socioeconómica, estímulo a la actividad escolar, ejercicio de rol normativo y el contacto con pares de riesgo.

El informe redactado a partir de una entrevista directa con el joven está a cargo de una licenciada en psicología, y el informe social, elaborado luego de una visita a su familia, corresponde a una licenciada en trabajo social. Estos escritos deben ser revisados por el Consejo Consultivo del Complejo, que funciona como un filtro correctivo de estos enunciados, en una instancia que podemos llamar la segunda escala del momento de producción. Del egreso del CAD puede seguirse la guarda judicial a cargo de familiares, o la continuidad de la prisión en otras de las cárceles del predio.

Sobre el tiempo de detención del joven hasta este momento, una de las entrevistadas de la SENAF, asegura que

(10) (...) cuando queda detenido, el proceso comienza por el Centro de Admisión, ahí está dos, tres, cuatro días, ahí se le hacen los estudios psicológicos al chico, social a la familia, y después es trasladado a distintos módulos (...) (Fragmento de entrevista 3 a psicóloga de los equipos técnicos de la SENAF).

Luego del relevamiento de los 40 expedientes radicados en los cuatro juzgados de Córdoba Capital, esta versión sobre el tiempo promedio de encierro en el CAD queda contestada. En suma, entre las horas de encierro en la unidad judicial y los días que suelen transcurrir durante esta primera estadía en el Complejo, el joven acumula comúnmente hasta 15 días de encierro.

Esta se constituye en una instancia de vinculación del joven judicializado con una verdad sobre la transgresión y su conducta transgresora que, a diferencia de otras instancias ${ }^{12}$, necesita de la pronunciación de la palabra por parte del joven.

12. Con estas otras instancias, nos referimos a las tres entrevistas que tres agentes de la cadena punitiva estatal mantienen con los niños y adolescentes supuestos autores de delitos. Las dos primeras, que realizan la policía al momento de la detención y el juez o jueza de turno (y en caso de delegación de funciones, el secretario o la secretaria) respectivamente, resultan en dos documentos anexados al expediente de la causa. El documento policial es titulado "acta de aprehensión" y el judicial es el titulado "contacto directo y personal". La tercera de las entrevistas es producida inmediatamente después del "contacto directo y personal", en la asesoría de niñez y juventud de turno. Las asesoras y sus auxiliares cumplen una doble función. Una es la representación complementaria (antes llamada asesoría promiscua) y consiste en el monitoreo y seguimiento del respeto de garantías en los procedimientos penales seguidos contra los niños y adolescentes. La otra es cumplida en la defensa pública del adolescente imputado o el niño al que se atribuye un delito. 
Es decir, asumimos la del CAD como la primera escena de indagación tribunalicia, donde no sería posible adecuar al joven a una verdad de sí mismo si el joven mismo no la sellara respondiendo a la pregunta que aparece transcrita en la mayoría de los informes "cqué te trajo hasta aquí?".

(11) (...) Entonces se ve todo lo que es factores de riesgo, factores de protección, qué es lo que hace falta, restitución de derechos, que siempre está presente frente a la vulneración. Lo criminológico en sí: bueno... está bien, tenés este delito, a ver... quépasó, qué circunstancias se dieron para llegar a esa instancia. Y en base a eso se va trabajando y se va elaborando un plan de abordaje individual (Fragmento de entrevista con integrante de la división de equipos técnicos, de la SENAF)

(12) (...) Muchos procesos van transcurriendo y no llegan a una sentencia (...), vos no sabés si lo cometió o no lo cometió oficialmente, lo que no quita que surja de la entrevista la transgresión a la ley o no. O sea, nosotros no trabajamos por el hecho puntual por el que él ha ingresado. Traduzco, si vos decís, bueno, mirá... yo entré abora por robo calificado, pero yo no estaba, porque estaba en el baile, por esto, por lo otro... y realmente creés lo que dice, que no estuvo, pero cuando vos desarrollás un poco para atrás, en el trabajo en equipo sale que sí venía robando, que venía haciendo, ¿̇me entendés? Entonces vamos más al trabajo de la conducta que al hecho puntual por el que entra (...) (Fragmento de entrevista con integrante de la división de equipos técnicos, de la SENAF)

El vigor de la práctica de indagación (palabra derivada del latín indagare, conducir a la presa al interior de un tejido en red), que construye la verdad que presupone, es provisto por el mismo acusado. En esta suerte de tribunales escabinos, compuestos de psicólogos y trabajadores sociales, el rótulo de supuesto autor de delito con que el joven espera la sentencia de declaración de responsabilidad penal, no llega a ser un obstáculo para otra investigación: la del porqué de el ser transgresor. En la pregunta "¿qué te trajo hasta aquí?" se encierra el presupuesto "sabes que estar aquí es consecuencia lógica de aquello que sabes que hiciste". La indagación interpela una respuesta que dé a esa correspondencia lógica (hecho no-probado / prisión) una validez que de otra forma no tendría.

De estos fragmentos de entrevistas, se desprende una idea central: los equipos técnicos de la SENAF que encaran el proceso que aquí reconocemos como de indagación cumplen un papel que consiste en componer una tríada que sobredetermina el futuro del proceso. Asocian 'circunstancias pasadas' reconstruidas en los relatos de los informes psicológicos y sociales del CAD y 'circunstancias presentes'

13. A la asesora-defensora pública corresponde la defensa del interés de la parte demandada y a la asesora-representante complementaria, el control del cumplimiento de los principios de legalidad y el debido proceso. 
designadas en los mismos informes con 'circunstancias futuras' consideradas deseables en un 'plan individual'. El 'abordaje' futuro de las tres circunstancias es representado como una competencia profesional de responsabilización. Es decir, la tríada de circunstancias, que 'se va trabajando en equipo', tiene por objetivo llegar a una verdad 'creíble' sobre 'lo que se dio para llegar a esta instancia'. Y este objetivo de veridicción, típico del paradigma de indagación que gobierna toda la práctica judicial de occidente, es alcanzado mediante una técnica específica. La competencia que hace de estos agentes del encierro técnicos y profesionales es doble: por un lado, consiste en aglutinar bajo lo individual del joven la mayor cantidad de circunstancias posibles: las pasadas que llevaron a este presente, las presentes que transcurren en el encierro, y las futuras. Por otro lado, en ampliar la cobertura temporal de esas circunstancias ('un poco para atrás'). Con todo, la verosilimitud de la verdad a la que se arribe dependerá de que el tiempo de lo que 'te trajo hasta acá', el tiempo del CAD y el tiempo que vendrá con el 'plan individual' sean lo más amplios posibles:

(13) (...) por esto, por lo otro... y realmente creés lo que dice, que no estuvo, pero cuando vos desarrollás un poco para atrás, en el trabajo en equipo sale que sí venía robando (...)

El joven interpelado por la autoridad del rito judicial - "ieh, tú!" (ALTHUSSER, 1984 [1970], p. 202), "¿quién eres?" (FOUCAULT, 2014 [2012], p. 233) - es un sujeto al cual se vincula una verdad sobre la peligrosidad juvenil. Una verdad que funciona como el principio organizador de la tríada de circunstancias de la que hablamos. Una que impregna esa historia abierta haciéndola verídica en tanto retrato individual requerido para la proyección de un 'plan'.

(14) (...) las transgresiones formarían parte de su vida cotidiana, habiendo naturalizado ya este comportamiento (...) (Informe psicólogico del CAD, Leg. 207, Exp. 1710632, fs. 139. Causa del Juzgado de $6^{\text {ta }}$ nominación, secretaría $5^{\text {ta }}$ ).

(15) (...) [El joven] conoce la dinámica institucional, por lo que pudo adaptarse fácilmente. Sin embargo, ha presentado conflictos aislados de transgresión a las reglas de la institución, como una manera de llamar la atención sobre su presencia en el lugar (...) (Informe psicológico en el CAD, Leg. 209, Exp. 1712739, fs. 142. Causa del Juzgado de $6^{\text {ta }}$ nominación, secretaría $5^{\text {ta }}$ ).

(16) (...) [El joven] reconoce haber robado y que nunca pensó que sus actos pudieran tener como consecuencia su internación. Se muestra reflexivo y angustiado, pudiendo comprender las consecuencias que sus conductas transgresoras le ocasionaron. En el gabinete se está 
trabajando con el adolescente para que pueda comprender y reflexionar sobre los factores que lo predispusieron a su actual situación (...) (Informe psicológico en el CAD, Leg. 182, Exp. 1802440, fs. 49. Causa del Juzgado de $7^{\text {ma }}$ nominación, secretaría $\left.7^{m a}\right)$.

Es en este punto común donde tienen anclaje el procedimiento de veridicción, institucionalizado en la indagación, y la exhibición virtuosa de "sensibilidad aguzada" que Villalta (2004) reconoce como cualidad distintiva autoatribuida por los jueces penales juveniles. El artilugio pedagógico de los agentes que aquí dramatizan discursos de jurisdicción consiste en instruir al joven en su historia y su encierro como circunstancias que se siguen lógicamente una de otra, y en esta composición como la condición de necesidad de un plan de 'abordaje' que responsabilice al sujeto por ambas circunstancias. "Ya no se trata de decir (...) dime si, en efecto, bas cometido el crimen de que se te acusa" (FOUCAULT, 2014 [2012], p. 244). El decir veraz sobre la propia subjetividad, que es requerido por parte de los niños y adolescentes desde su entrada al CAD, es un requerimiento de un devenido juez que reclama: "no te limites a decir lo que bas becho sin decirme al mismo tiempo y por su intermedio quién eres" (FOUCAULT, 2014 [2012], p. 233). Entonces, el sistema jurídico en el que se encastran los procedimientos de indagación busca no sólo "hacer surgir una subjetividad que mantenga con su crimen una relación significante" (FOUCAULT, 2014 [2012], p. 229), sino también comprometer al sujeto con un singular concepto de responsabilidad. En el contexto de prisión del CAD, el ser responsable del joven es alcanzado sólo si éste comprende (con el sentido cognitivo y pedagógico del término) lo que el vínculo asimétrico con el profesional le exige comprender. En base a lo dicho, podemos describir el objeto de comprensión en un enunciado como el que sigue: sus circunstancias históricas, que serán sistematizadas y categorizadas con mayor precisión a medida que transcurra el tiempo de encierro, las circunstancias del encierro mismo y la relación de causa-efecto entre ambas, son productos de su libre elección.

(17) (...) [El joven] no ha presentado dificultades de adaptación institucional, por lo que se encuentra respondiendo a las mismas de manera adecuada (...) (Informe psicosocial en el Módulo II, Leg. 159, Exp. 1834967, fs. 174. Causa del Juzgado de $7^{\text {ma }}$ nominación, secretaría $8^{\text {va }}$.

(18) (...) Desde este equipo técnico, se continuará trabajando con [el joven] mediante un abordaje reflexivo que contribuya a disipar sus miedos y temores, que colabore a que Walter asuma con responsabilidad su actual situación (...) (Informe psicosocial en el Módulo II, Leg. 262, Exp. 1785978, fs. 114-115. Causa del Juzgado de $4^{\text {ta }}$ nominación, secretaría $4^{\text {ta }}$ ) 
(19) (...) A las entrevistas, [el joven] se presenta angustiado. En cada momento expresa haber tenido algún problema diferente con sus compañeros. Presenta un discurso manipulador y constantemente crea demandas por las cuales exige ser atendido (...) (Informe psicosocial en el Módulo IV, Leg. 174, Exp. 1841178, fs. 137. Causa del Juzgado de $7^{\text {ma }}$ nominación, secretaría $8^{\text {va }}$ ).

(20) (...) presenta dificultades para acatar las normativas implementadas a partir de las figuras de autoridad, como tampoco lograría visualizar las situaciones de riesgo que esto implicaría para su persona. Así mismo, denota angustia y ansiedad ante la resolución legal de su situación. Siendo todo cuanto se puede informar por el momento, saludo a usted muy atte. (...) (Informe psicológico en el CAD, Leg. 209, Exp. 1712739, fs. 104-105. Causa del Juzgado de $6^{\text {ta }}$ nominación, secretaría $\left.5^{\text {ta }}\right)$.

El joven puede asumir las consecuencias del ejercicio de su libre albedrío o ponderarlas sin tomarlas a cargo. El contexto de encierro, que es el contexto de producción de su responsabilidad, debe ser, y esta es la norma de la responsabilización, un laboratorio donde el sujeto ensaye el reconocimiento de sus circunstancias como elegidas. Esto vuelve la respuesta del joven en la entrevista un punto neurálgico en el proceso: es al mismo tiempo un evento de interpretancia -porque entraña cierta habilidad para encausar su respuesta en la dirección interpelada-, un índice del compromiso asumido a través de elecciones tenidas por libres, y el objeto de una nueva interpretancia, el argumento del juez, que accederá a él con la mediación del informe del psicólogo.

Nuestros rodeos analíticos tienen por objeto describir una operación que ha sido naturalizada en la administración de justicia penal juvenil y el sistema de protección. El 'Plan de abordaje individual' elaborado en el CAD no es planificado, ni será abordado por el joven, que definitivamente no es el individuo al que hace referencia el lexema 'individual'. Dicho plan representa:

a- las circunstancias futuras de su ser-joven, que llevarán inscritas las marcas férreas de su encierro,

b- el proyecto de adecuación de sus circunstancias pasadas y presentes a ese ser futuro y

c- el proyecto de adecuación del joven presente al individuo responsable (por libre de elección) que el plan pondera como signo de responsabilidad.

En este sentido 'la angustia' y 'los miedos' designan mecanismos de negación del sí mismo. Estos son empleados por quien sabe lo que hizo y sabe quién es, pero se resiste a una bermenéutica del yo (FOUCAULT, 1990) que le señalaría quién debe ser. Los artilugios pedagógicos que reconocemos en los discursos profesionales 
de esta prisión establecen que un riguroso autoexamen por parte del joven derivará inexorablemente en la comprensión de sus circunstancias presentes como consecuencias naturales de su pasado. El aprendizaje (y por lo tanto la enseñanza) de determinadas circunstancias pasadas y presentes como propias, elegidas y consecuentes una de otra es la vía para eludir la angustia y el miedo. Un plan de abordaje individual funciona cuando el joven efectivamente hace suyo el sujeto informado de sus circunstancias que han construido para él. 'Los altos montos de angustia' y 'miedo' son propios de quien, por la bruma del presente, no puede divisar lo que se precipita delante de él.

\subsection{El joven responsabilizado}

En este orden discursivo, la construcción del libre albedrío es el punto de apoyo de una imputación de responsabilidad, pero, al mismo tiempo, y por extensión, el de un borramiento de las huellas del dispositivo institucional en el castigo. En el transcurso del tiempo que dure el castigo penal, según postula una racionalidad filantrópica, el joven recibe una terapia penal. El joven debe responder a la exigencia de asumir como optados dos nexos causales: entre su voluntad y el hecho y entre su voluntad y el castigo. Es incontestable que la correspondencia entre el castigo y el hecho, es establecida por la libre intervención de la voluntad.

En nuestro análisis, apostamos a reponer las huellas de la agencia institucional que el discurso experto borra en sus representaciones de las prácticas de castigo del Complejo. El Estado es un escenario de interlegalidades en el cual distintas agencias, como la de la justicia penal juvenil, contribuyen a la formación de un campo relativamente autónomo incluido en una jerarquía de niveles jurídicos. Las innovaciones legislativas que reseñamos al inicio de este artículo producen en las prácticas de administración del castigo juvenil una multiplicidad de efectos que ilustran una de las formas posibles de esa interlegalidad.

En esta misma dirección, la superposición de las leyes nacional y provincial de protección integral con el Régimen Penal de Minoridad aprobado en 1980 debe llevar, en última instancia, a tematizar dos preguntas: ća qué ámbitos del Estado corresponde el gobierno de la juventud problemática? (DAROQUI, LÓPEZ y CIPRIANO GARCÍA, 2012) y ćcómo contribuyen esos ámbitos y sus respectivas legalidades a la forma distintiva de administración del Estado penal en la población de jóvenes que seleccionan? (WACQUANT, 2015 [1999]).

Las respuestas a estas dos preguntas son capaces de dar cuenta de dos dimensiones del problema, estrechamente conectadas: i) el campo heterogéneo donde se posicionan los agentes de las políticas penales, el sentido que inviste sus prácticas en la lógica del campo y los discursos de caracterizan sus justificaciones; 
ii) los posicionamientos diferenciales de los agentes judiciales, así como de los profesionales de los organismos de aplicación, en el proceso de construcción de un referente normativo de joven irresponsable, y de su contracara, el joven responsable.

El juez, que conserva su autorización formal, habita un medio de interlegalidades estatales (URTEAGA, 2017; DE SOUSA SANTOS, 2009) donde otros enunciadores disputan el poder de investir de sentido al lexema protección. Este significante, en la formalidad jurídica, designa un paradigma que orienta el reconocimiento, en este caso, judicial, de los jóvenes como sujetos activos de derechos y responsabilidades. Sin embargo, en otro plano, el de los mecanismos judiciales de simbolización (DE SOUSA SANTOS, 2009) que nos dedicamos a reconstruir, designa el horizonte (el "interés superior del niño") declamado por un dispositivo institucional de castigo.

\section{CONCLUSIONES}

Un conjunto de prácticas significantes compuesto por instrumentos legales, como el decisivo inciso c) del artículo 87 de la Ley $9.944^{13}$, y por las distintas decisiones judiciales durante las causas, son condiciones determinantes del trayecto del encierro de los jóvenes. Pero en el contexto del despliegue efectivo del régimen local de responsabilidad penal juvenil, otros agentes y otras prácticas se acoplan a ese conjunto de condiciones determinantes, y pugnan por el reconocimiento de su capacidad definitoria propia del sistema de reglas.

En otras palabras, otros actores justifican la profesionalidad de su intervención en la administración del sistema penal. Mediante una serie de estrategias de interpelación de la palabra del joven, las trabajadoras sociales y psicólogas del CAD, se incorporan al staff de sujetos de indagación. La prisión de los jóvenes es generalmente justificada en los autos interlocutorios de los jueces como la privación cautelar de la libertad que garantiza los fines del proceso. Es decir, los tribunales penales embarcados en la indagación de la verdad judicial y

13. En el séptimo título de la ley provincial de protección integral, se establece, como una de las medidas provisorias de protección previstas para el tiempo que dure la investigación preparatoria. Se enuncia la eventualidad de la privación de libertad "cuando la niña, niño o adolescente careciera de familia o de terceros en condiciones de cumplir eficientemente la guarda y apoyar la libertad asistida". En un artículo posterior, el 100, la normativa otorga al Juez Penal Juvenil la competencia de dictar medidas de coerción y cautelares. Actualmente, las medidas de protección, coerción y cautelares son dispuestas por los mismos jueces que llevan a cabo la etapa de investigación preparatoria. Es decir, actúan como agentes de acusación, jueces de garantía y jueces de ejecución de la pena. 
en la recolección y valoración de la prueba interpelan un joven preso por protegido, sin poder de palabra. Mientras la investigación penal transcurre, un proceso de indagación paralelo transcurre en los tribunales socioeducativos, donde enunciadores pedagógicos arriban a una verdad sobre las circunstancias mismas del encierro.

En esta investigación simultánea que reconocemos delineada en la prisión del CAD aparece un singular requisito: la verdad de la correspondencia entre las circunstancias del joven debe ser pronunciada en sus propias palabras. Una primera batería de procedimientos tribunalicios, los jurisdiccionales, deposita la responsabilidad por el castigo en un coro de profesionales (FOUCAULT, 2002). Pero otras escenas tribunalicias, la segunda batería, no menos compleja pero sí más solapada, deposita la responsabilidad por el castigo en el castigado.

¿Cuál es el papel de los artilugios pedagógicos puestos en marcha en el dispositivo penal juvenil en relación con la práctica de indagación? El Estado Penal reconocerá un sujeto responsable siempre que por responsabilidad se entienda la propiedad del joven que coloca su firma al pie del relato oficial de las condiciones de posibilidad de su encierro. El enunciado elaborar el trauma equivale, en este sentido, a la respuesta que todo joven que se precie de responsable debería dar a la pregunta '¿qué te trajo hasta aquí?: 'yo mismo'. Un joven responsabilizado elabora el trauma aceptando dos condiciones: (i) que debe hacerlo, (ii) que él mismo se lo ha infligido.

Sin dudas, la transición hacia un sistema de protección integral intenta solventar una deuda histórica en materia de protección de derechos, porque reconoce a niñas, niños y adolescentes como sujetos de derechos y no más como objetos de tutela estatal. Aquí no desconocemos ni contradecimos el hecho de que los eventos legislativos que erigieron este sistema y la voluntad política de mejorarlo constituyen puntapiés invaluables para revertir la orientación coactiva y criminalizadora de la pobreza. Nos dirigimos, antes bien, a pronunciar una voz entre otras que, desde el campo académico, llame la atención sobre un hecho incontestable. La transición hacia el paradigma de la protección integral de los derechos de las niñas, niños y adolescentes se da en simultáneo a la transición al Estado penal en desmedro del Estado social. Y, entonces, el análisis de los discursos no puede soslayar un aspecto clave de sus condiciones de producción: la palabra de los agentes del sistema penal juvenil se encuentra determinada, en última instancia, por "la interpenetración creciente de los sectores social y penal del Estado poskeynesiano" (WACQUANT, 2015 [1999], p. 110). 


\section{REFERENCIAS}

ALTHUSSER, L. (1970). Ideologías y aparatos ideológicos de estado, trad. Alberto Pla y José Sazbón. Buenos Aires: Nueva Visión, 1988.

ANICETO, P. (2017a). Una reflexión sobre el carácter agonístico de la práctica de jurisdicción. La construcción de ámbitos de justicia. Nómadas, Revista Crítica de Ciencias Sociales y Jurídicas, v. 53, pp. 1-18. Disponible en http://www.theoria.eu/ nomadas/53/paulodamiananiceto.pdf

ANICETO, P. (2017b). La práctica jurídica como el evento de su dramatización. Las miseen-scène del campo judicial. Foro, Nueva época, v. 20, n. 1, pp. 219-238. Disponible en https://revistas.ucm.es/index.php/FORO/article/view/57534/51827

CLEMMER, D. (1958). The prison community. Nueva York: Rinehart \& Winston.

CULIOLI, A. (1995). Chapter 3. Notional domains. En: Cognition and representation in linguistic theory, trad. Michel Liddle. Philadelphia: John Benjamins, pp. 45-84.

DAROQUI, A., LÓPEZ, A. L. y CIPRIANO GARCÍA, R. F. (coord.). (2012). Sujeto de castigos: Hacia una sociología de la penalidad juvenil. Rosario: Homo Sapiens Ediciones.

DE SOUSA SANTOS, B. (2009). Sociología jurídica crítica. Para un nuevo sentido común en el derecho. Madrid: Editorial Trotta.

DAROQUI, A. y LÓPEZ, A. L. (2012a). Introducción. En: Daroqui, A., López, A. L. y Cipriano García, R. F. (coords.), Sujeto de castigos: Hacia una sociología de la penalidad juvenil. Rosario: Homo Sapiens Ediciones, pp. 49-59.

DAROQUI, A. y LÓPEZ, A. L. (2012b). La cadena punitiva: actores, discursos y prácticas enlazadas. En Daroqui, A., López, A. L. y Cipriano García, R. F. (coords.), Sujeto de castigos: Hacia una sociología de la penalidad juvenil. Rosario: Homo Sapiens Ediciones, pp. $101-106$.

FASSIN, D. (2017). Castigar, trad. Antonio Oviedo. Buenos Aires: Adriana Hidalgo, 2018.

FOUCAULT, M. (2012). Obrar mal, decir la verdad. La función de la confesión en la justicia, trad. Horacio Pons. Buenos Aires: Siglo XXI, 2014.

FOUCAULT, M. (2002). Vigilar y castigar. Nacimiento de la prisión, trad. Aurelio Garzón del Camino. Buenos Aires: Siglo XXI, 1975. 
FOUCAULT, M. (1990). Tecnologías del yo, trad. Mercedes Allendesalazar Olaso. Barcelona: Paidós.

GARCÍA MÉNDEZ, E. (1988). Para una historia del control penal de la infancia: la informalidad de los mecanismos formales de control social. Capítulo Criminológico, v. 16, pp. $43-73$.

GARLAND, D. (1990). Castigo y sociedad moderna. Un estudio de teoría social, trad. Berta Ruiz de la Concha. México: Siglo XXI, 1999.

GUEMUREMAN, S. (2011). La cartografía moral de las prácticas judiciales en los Tribunales de Menores. Los tribunales orales de la Ciudad de Buenos Aires. Buenos Aires: Editores del Puerto.

HATHAZY, P. (2014). De la "seguridad ciudadana" a la "seguridad pública" en democracia: Juristas, políticos y policías en la construcción de las políticas de seguridad en Córdoba, Cuestiones de Sociología, v. 10, pp. 2-10.

JACKSON, B. (1988). Law, Fact and Narrative Coberence. Merceyside: Deborah Charles Publications.

KILEY, D. (1996). Real Stories: True Narratology, False Narrative and a Trial. Australian Journal Of Law And Society, v. 12, pp. 37-48. Disponible en http://www.austlii.edu.au/ au/journals/AUJlLawSoc/1996/7.pdf

LANDOWSKI, E. (1993). La sociedad figurada. Ensayos de sociosemiótica, trad. Gabriel Hernández Aguilar. México DF: Fondo de Cultura Económica, 1993.

LANDOWSKI, E. et al (1976). Análisis semiótico de un discurso jurídico. La ley comercial sobre las sociedades y los grupos de sociedades. En Greimas, A. J., Semiótica y Ciencia Sociales, trad. José Adolfo Arias Muñoz. Madrid: Fragua, 1980.

LERCHUNDI, M. y BONVILLANI, A. (2014). Jóvenes y código de faltas. Una "experiencia" de detención. Justicia Juri, v. 10, n 1, pp. 43-52.

LUCERO, M. V. (2013). Infancia y derechos: radiografía crítica de la Ley 26.061: escenarios provinciales normativos, institucionales y jurisprudenciales. Buenos Aires: EDUDEBA.

LUGONES, G. (2012). Obrando en autos, obrando en vidas. Formas y fórmulas de Protección Judicial en los tribunales Prevencionales de Menores de Córdoba, Argentina, a comienzos del siglo XXI. Rio de Janeiro: E-papers.

MAINGUENEAU, D. (1984). Genèses du discours. Bruxelles-Liège: Mardaga. 
MESSUTI, A. (2008). La justicia deconstruida. Barcelona: Edicions Bellaterra.

MORTUREUX, M-F. (1993). Paradigmes désignationnels, Semen. Revue de sémiolinguistique des textes et discours, v. 8. Disponible en http://journals.openedition. org/semen/4132

PLANTIN, Ch. (2005). La argumentación. Historia, teorías, perspectivas, trad. Nora Isabel Muñoz. Buenos Aires: Biblos, 2012.

ROLDÁN, E. M., DAHBAR, M. V. (2013). Los límites de la novedad. El caso del Código de Faltas de Córdoba (Argentina).RevistaFar@, v. 16, pp. 57-72.

SABSAY, D. (2006). La dimensión constitucional de la Ley 26.061 y del decreto 1293/2005. En: García Méndez, E. (comp.), Protección Integral de niñas, niños y adolescentes. Buenos Aires: Ediciones del Puerto/Fundación Sur, pp. 15-25.

STYGALL, G. (1994). Trial language: differential discourse processing and discursive formation. Amsterdam/ Philadelphia: John Benjamins.

URTEAGA, P. (2017). La sentencia de Bagua y las densidades de la justicia. En: Jugo Viera, J. M. (ed.), La Sentencia del caso "Baguazo" y sus aportes a la Justicia Intercultural. Lima: Coordinadora Nacional de Derechos Humanos, pp. 43-60.

VILLALTA, C. (2004). Una filantrópica posición social: los jueces en la justicia de menores. En: Tiscornia, S.(comp.), Burocracias y violencia. Estudios de antropología jurídica. Buenos Aires: Editorial Antropofagia, pp. 281-326.

WACQUANT, L. (2009). Castigar a los pobres. El gobierno neoliberal de la inseguridad social, trad. Margarita Polo. Barcelona: Gedisa, 2013.

WACQUANT, L. (1999). Las cárceles de la miseria, trad. Horacio Pons. Buenos Aires: Manantial, 2015.

Recebido: 20/03/2020

Aceito: 8/04/2020

Publicado: $12 / 04 / 2020$ 